Brazilian Journal of Forensic Sciences, Medical Law and Bioethics

\title{
O Uso do Drone de Baixo Custo em Aerofotogrametria e sua Aplicação na Perícia Ambiental Criminal
}

\section{The Use of a Low-cost Drone in Aerophotogrametry and Its Application in the Environmental Forensic Investigation}

\author{
André Carrara Cotomácio*, Bruno Lazzari de Lima \\ Instituto de Criminalística (IC), Superintendência de Polícia Técnico-Científica/SP, Brasil \\ * Corresponding author. Address: Av. Henriqueta Mendes Guerra, 1018 - Vila São João, Barueri - SP, \\ 06401-160, Brazil. Phone: (11) 4208-3539. E-mail: andrecotomacio@gmail.com
}

Received 16 April 2020

Resumo. O presente estudo tem o objetivo evidenciar a possibilidade da obtenção de elementos técnicos de aplicação pericial com o uso da tecnologia de aquisição de imagens por meio de veículos aéreos não tripulados, a fim de se produzir relevante prova material por meio do laudo pericial criminal. Para tanto, foi utilizada uma aeronave remotamente pilotada (ARP), popularmente conhecida como drone, de baixo custo de aquisição, oportunizando a produção de um ortomosaico mediante processamento digital. Os resultados obtidos possibilitaram a caracterização da supressão de vegetação decorrente do parcelamento irregular do solo, sendo posteriormente discutidas as necessidades e limitações do uso de aeronaves de baixo custo para fotogrametria.

Palavras-chave: Perícia forense; Drone; Aerofotogrametria; Área de preservação permanente; Perícia ambiental.

Abstract. This study aims to evidence the obtaining of technical elements for forensic application through image acquisition by UAV (unmanned aerial vehicle), in order to produce relevant material evidence for an expert report. For this purpose, a low cost remotely piloted aircraft (RPA) was used in order to obtain an orthomosaic through digital processing. The results obtained allow characterizing the suppression of vegetation as result from irregular land subdivision. What is more, the needs and limitations of the use of low-cost aircraft for photogrammetry was discussed in the present case report. 
Keywords: Forensic expertise; RPA; Aerial photogrammetry; Permanent preservation areas; Environmental forensics.

\section{Introdução}

\subsection{Perícia de crimes contra o meio ambiente}

Segundo o Artigo 1丷, inciso III, da Resolução CONAMA 237/1997, estudos ambientais "são todos e quaisquer estudos relativos aos aspectos ambientais relacionados à localização, instalação, operação e ampliação de uma atividade ou empreendimento, apresentado como subsídio para a análise da licença requerida, tais como: relatório ambiental, plano e projeto de controle ambiental, relatório ambiental preliminar, diagnóstico ambiental, plano de manejo, plano de recuperação de área degradada e análise preliminar de risco"1.

A perícia ambiental consiste em um estudo ambiental que objetiva a obtenção e análise de vestígios que possam auxiliar na solução de crimes e danos ambientais, proporcionando condições necessárias para uma decisão judicial embasada em conhecimentos técnicos. No Brasil a criação da Lei no 9.605/98, que trata sobre os crimes ambientais, tornou essa nova modalidade de perícia um importante instrumento na preservação ambiental, através da responsabilização e aplicação de sanções tanto na esfera penal quanto administrativa, aos causadores de tais danos, sendo considerados agora crimes ambientais ${ }^{2}$. Nesse sentido, as infrações decorrentes da degradação ambiental provocada pelo ser humano enquadram-se, basicamente, na ocupação de espaços ambientais juridicamente protegidos; na poluição atmosférica, do solo ou da água; no desmatamento, no uso degradante do solo, ou mesmo pela ameaça ou lesão à fauna ${ }^{3}$.

Contudo, uma vez que o levantamento completo de grandes áreas, por meio dos métodos fotográficos convencionais é difícil e demorado, faz-se necessário o desenvolvimento e aplicação de novas tecnologias que permitam, com excelência, praticidade e agilidade, a realização tal atividade ${ }^{4}$. Dentre essas tecnologias destaca a utilização do sensoriamento remoto $(\mathrm{SR})$ via satélite e de veículos aéreos não tripulados (VANTs), ou mais popularmente conhecidos como drones. Um exemplo dessa possível aplicação às perícias de meio ambiente está atrelado à técnica de fotogrametria digital que consiste na reconstrução de um espaço tridimensional, a partir de um conjunto de imagens bidimensionais adquiridas por meio de sensores ou câmeras fotográficas ${ }^{5}$. Quando essas câmeras se encontram embarcadas em 
aeronaves, tem-se a aerofotogrametria (fotogrametria efetuada em um aerolevantamento).

No contexto da criminalística, a utilização de tais tecnologias implica na melhoria da qualidade da prova pericial, uma vez que são obtidas imagens aéreas em melhor resolução do que as de satélite. Além disso, é possível a redução no tempo dos exames (a exemplo de um levantamento topográfico), a economia de recursos e a redução da exposição a riscos (alcance de locais de difícil acesso) ${ }^{6}$.

\section{2. $O$ uso de drones nas perícias ambientais}

Para a Força Área Brasileira (FAB $)^{7}$, a palavra inglesa drone (em português zangão), é apenas um apelido informal utilizado para caracterizar todo e qualquer objeto voador não tripulado, seja ele de uso profissional ou recreativo ${ }^{7}$. A terminologia oficial, prevista pelos órgãos reguladores brasileiros do transporte aéreo, define tais equipamentos como VANT (Veículo Aéreo Não Tripulado).

Do mesmo modo, podemos classificar tais aeronaves em duas subcategorias. A primeira é denominada RPA (Remotely-Piloted Aircraft ou, em português, Aeronave Remotamente Pilotada). Nessa condição, o piloto não está a bordo, mas controla aeronave remotamente, frequentemente por meio de rádio frequência. Diferente da primeira, a chamada "aeronave autônoma", uma vez programada, não permite intervenção externa durante a realização do voo, sendo estas proibidas no Brasil ${ }^{7}$. Assim, sempre que nos referimos um VANT, tratar-se-á de uma RPA.

Embora os primeiros equipamentos tenham sido desenvolvidos com finalidades militares, atualmente os mesmos voltaram-se principalmente ao entretenimento, seja em atividades recreativas ou relacionadas à indústria cinematográfica ${ }^{8}$.

Pasqualini ${ }^{9}$ foi o pioneiro na perícia criminal brasileira a observar grandes vantagens em se agregar o uso de VANTs na realização dos exames para a realização de fotografias aéreas, sendo possível produzir, após o seu processamento, alguns produtos relevantes para o uso pericial tais como: mosaico de imagens (imagem produzida a partir de várias imagens sobrepostas parcialmente); ortofotos (imagens que possibilitam a obtenção de medidas métricas); e imagens tridimensionais (imagens produzidas a partir de uma nuvem de pontos, das quais pode-se observar e medir o volume de objetos e estruturas). Medeiros, 
Patriota e Torres $^{10}$ posteriormente ratificaram o trabalho de Pasqualini ${ }^{9}$ quanto ao uso de VANTs do tipo RPA em perícias de engenharia forense e de meio ambiente, tendo considerado o multirrotor como aeronave mais adequada a estas aplicações, devido à versatilidade, facilidade de transporte, montagem, operação e baixo custo financeiro.

Contudo, a automação na aquisição de imagens, possibilitada pelos VANTs, aumenta o número de usuários, mas não o de especialistas. Para tanto, é preciso agregar os conhecimentos necessários para a produção de informação que possa ser devidamente utilizada para fins periciais, principalmente por meio do levantamento aerofotogramétrico.

\subsection{Levantamento aerofotogramétrico do local}

O levantamento de dados topográficos para perícia por meio da aerofotogrametria permite a visualização em três dimensões de um local de interesse, bem como o cálculo de distâncias, volumes e massas, medições planialtimétricas, além do monitoramento visual da superfície ${ }^{11}$. Para tal, faz-se necessária a criação de modelos digitais do terreno (MDT) em alta resolução e alta qualidade, o que demanda significativo tempo, além de elevado investimento financeiro, especialmente em hardware e software, utilizados na obtenção e processamento das imagens ${ }^{12}$.

Segundo Fonstad et al. (2013) ${ }^{12}$, a abordagem fotogramétrica Structure from Motion (SfM) ou "Estrutura pelo Movimento", foi desenvolvida com o objetivo de levantamentos tridimensionais de edifícios ou objetos pequenos, de forma mais rápida e barata. A técnica consiste na obtenção de fotos de um local em diferentes perspectivas sendo, a partir de pontos característicos coincidentes, realizados cálculos para a reprodução digital da área. O produto básico do processo SfM é uma nuvem de pontos, que pode ser georreferenciada a partir de um pequeno número de pontos de controle coletados em campo ou do posicionamento GPS no momento da aquisição da imagem. A nuvem de pontos georreferenciada pode então ser usada para criar uma variedade de produtos de elevação digital. Finalmente, a utilização de VANTs aliados à fotogrametria SfM, tornou-se uma poderosa ferramenta para a reprodução topográfica de locais relacionados à crimes contra o meio ambiente ${ }^{12}$.

No entanto, a obtenção de imagens de alta resolução (>4 m/pixel), necessárias no desenvolvimento de SfM, requer a utilização de equipamentos cujo 
custo, embora baixo em países de primeiro mundo, muitas vezes pode ser proibitivamente caro em países como o Brasil, tendo em vista os elevados impostos de sobre importação. Assim o objetivo deste trabalho consiste na descrição de um protocolo operacional simples e facilmente reprodutível, para a obtenção de imagens, bem como seu processamento, a partir de equipamentos de baixo custo, voltado à peritos criminais que não dispõem de equipamentos mais robustos em seus institutos de criminalística.

Para isso, aqui será apresentada a aplicabilidade do SfM em um local de loteamento clandestino (parcelamento irregular do solo), a fim de se evidenciar a existência de supressão de vegetação, aplicando-se um protocolo dividido em quatro etapas distintas e executadas de forma sequencial ${ }^{13}$ : (a) Planejamento de voo; (b) Levantamento de campo e (c) Processamento (d) Análise do impacto.

\section{Planejamento de voo}

Segundo as descrições do fabricante ${ }^{14}$, o DJI Spark é um minidrone que conta com todas as tecnologias presentes nos demais equipamentos da marca, incluindo opções automatizadas de controle de voo, estabilizador mecânico e uma câmera. Suas especificações técnicas encontram-se descritas na Tabela 1.

Tabela 1. Especificações técnicas do DJI Spark.

\begin{tabular}{|l|l|}
\hline Peso de decolagem & $300 \mathrm{~g}$ \\
\hline Velocidade máxima & $50 \mathrm{~km} / \mathrm{h}$ no Modo Esportivo sem vento \\
\hline $\begin{array}{l}\text { Altitude máxima de } \\
\text { serviço }\end{array}$ & $4000 \mathrm{~m}$ acima do nível do mar. \\
\hline Tempo máximo de voo & 16 minutos (sem vento a uma velocidade constante de $20 \mathrm{~km} / \mathrm{h}$ ) \\
\hline $\begin{array}{l}\text { Sistema de } \\
\text { posicionamento por } \\
\text { satélite }\end{array}$ & GPS/GLONASS \\
\hline Estabilização & Mecânica de 2 eixos (inclinação, rotação) \\
\hline $\begin{array}{l}\text { Sistema de detecção de } \\
\text { obstáculos }\end{array}$ & $\begin{array}{l}0,2-5 \mathrm{~m}(1-16 \text { pés) / Detecta superfícies reflexivas difusas }(>20 \%) \\
\text { maiores que } 20 \text { x } 20 \text { cm (paredes, árvores, pessoas, etc.) }\end{array}$ \\
\hline Características da câmera & $\begin{array}{l}1 / 2.3^{\prime \prime} \text { CMOS / Píxeis efetivos: } 12 \text { MP / Lente: } \\
\text { FOV } 81.9^{\circ} 25 \mathrm{~mm} \text { (formato equivalente a } 35 \mathrm{~mm} \text { ) f/2.6 (distância } \\
\text { de disparo: } 2 \mathrm{~m} \text { a } \infty \text { ) / ISSO: } 100 \text { - } 1600 / \text { Velocidade do } \\
\text { Obturador: } 2-1 \text { a } 8000 \text { s. }\end{array}$ \\
\hline
\end{tabular}

O pesquisador Jerry Davis ${ }^{15}$, do Departamento de Geografia e Meio Ambiente da Universidade de São Francisco (EUA), desenvolveu um método de mapeamento aéreo aplicado especificamente ao DJI Spark, indicando que o 
equipamento pode ser utilizado para trabalhos mais simples em pequenas áreas para fotografia aérea, apesar de ser um modelo pouco robusto e muitas vezes desaconselhado para este tipo de mapeamento, principalmente por sua baixa autonomia.

Contudo, para trabalhos mais robustos (como o de levantamento topográfico, por exemplo) 0 autor ${ }^{15}$ ressalta ser necessária a utilização de pontos de controle no solo, devido à baixa precisão de seu Sistema de Posicionamento Global (GPS) embarcado. Todavia, o referido procedimento também se faz necessário em aeronaves mais robustas existentes no mercado que não possuam sistemas de correção de posicionamento, seja em tempo real (RTK - Real Time Kinematic), ou após o voo (PPK - Post Processed Kinematic), o que não representaria, necessariamente, uma desvantagem.

Noutro giro, Jerry Davis ${ }^{15}$ destaca que os dispositivos de segurança contra obstáculos, o posicionamento visual e as proteções da hélice do DJI Spark tornam o voo seguro em locais difíceis com sinal GPS limitado, sendo uma alternativa barata e versátil e que pode ser aplicada, com o método adequado e ciente de suas limitações, para a aplicação básica em fotogrametria na produção de ortomosaicos.

O aerolevantamento com esse drone deve ser realizado de forma planejada, respeitando-se parâmetros que podem ser predefinidos para voos manuais, adaptando-se a metodologia proposta pela CIRCULAR TÉCNICA ํo 75 da EMBRAPA - "Planos de Voo Semiautônomos para Fotogrametria com Aeronaves Remotamente Pilotadas de Classe $3^{\prime \prime 16}$. O referido documento estabelece que 0 mapeamento se inicia com a definição de um plano de voo que seja adequado para o objetivo do exame que se pretende realizar, sendo que o sucesso no desempenho dos trabalhos envolve diversas possibilidades de combinações de alturas de voo, velocidade de cruzeiro da RPA, configuração das câmeras, características do ambiente a ser mapeado e sobreposição lateral e longitudinal das linhas de sobrevoo ${ }^{16}$.

Seguindo a mesma metodologia e, com base nas especificações de câmera do drone (Tabela 1), foram estabelecidos na Tabela 2 os parâmetros de voos manual para o modelo Spark, visando à geração de imagens ortorretificadas. $O$ mesmo método também pode ser aplicado a outros drones menos robustos, desde que com especificações técnicas similares. 
Tabela 2. Parâmetros do plano de voo para a RPA DJI SPARK.

\begin{tabular}{|c|c|c|c|c|c|c|c|c|c|c|}
\hline \multicolumn{3}{|c|}{ DADOS DO PLANO DE VOO } & \multicolumn{3}{c|}{ FOTO/ORTOFOTO } & \multicolumn{2}{|c|}{ OVERLAP } \\
\hline $\begin{array}{l}\text { Altura } \\
\text { de voo } \\
(\mathrm{m})\end{array}$ & $\begin{array}{c}\text { Altura } \\
\text { de voo } \\
(\mathrm{ft})\end{array}$ & $\begin{array}{c}\text { Velocidade } \\
(\mathrm{m} / \mathrm{s})\end{array}$ & $\begin{array}{c}\text { Intervalo } \\
\text { entre as } \\
\text { fotos }(\mathrm{s})\end{array}$ & $\begin{array}{c}\text { Distância } \\
\text { entre as } \\
\text { linhas de } \\
\text { voo }(\mathrm{m})\end{array}$ & $\begin{array}{c}\text { Cobertura } \\
\text { horizontal } \\
\text { da foto } \\
(\mathrm{m})\end{array}$ & $\begin{array}{c}\text { Cobertura } \\
\text { vertical da } \\
\text { foto }(\mathrm{m})\end{array}$ & $\begin{array}{c}\text { Área de } \\
\text { cobertura } \\
\text { da foto } \\
\left(\mathrm{m}^{2}\right)\end{array}$ & $\begin{array}{c}\text { GSD } \\
(\mathrm{cm} / \text { pixel })\end{array}$ & $\begin{array}{c}\text { Lateral } \\
(\%)\end{array}$ & $\begin{array}{c}\text { Longitudinal } \\
(\%)\end{array}$ \\
\hline 10 & 32,8 & 1 & 2 & 3 & 15,4 & 11,5 & 177,3 & 0,4 & $80 \%$ & $83 \%$ \\
\hline 20 & 65,6 & 2 & 2 & 5 & 30,8 & 23,1 & 709,3 & 0,8 & $84 \%$ & $83 \%$ \\
\hline 30 & 98,4 & 3 & 2 & 7 & 46,1 & 34,6 & $1.595,8$ & 1,2 & $85 \%$ & $83 \%$ \\
\hline 40 & 131,2 & 4 & 2 & 10 & 61,5 & 46,1 & $2.837,1$ & 1,6 & $84 \%$ & $83 \%$ \\
\hline 50 & 164,1 & 5 & 2 & 12 & 76,9 & 57,7 & $4.432,9$ & 1,9 & $84 \%$ & $83 \%$ \\
\hline 60 & 196,9 & 6 & 2 & 14 & 92,3 & 69,2 & $6.383,4$ & 2,3 & $85 \%$ & $83 \%$ \\
\hline 70 & 229,7 & 7 & 2 & 17 & 107,6 & 80,7 & $8.688,5$ & 2,7 & $84 \%$ & $83 \%$ \\
\hline 80 & 262,5 & 8 & 2 & 19 & 123,0 & 92,3 & $11.348,2$ & 3,1 & $85 \%$ & $83 \%$ \\
\hline 90 & 295,3 & 9 & 2 & 21 & 138,4 & 103,8 & $14.362,6$ & 3,5 & $85 \%$ & $83 \%$ \\
\hline 100 & 328,1 & 9 & 2 & 24 & 153,8 & 115,3 & $17.731,6$ & 3,9 & $84 \%$ & $84 \%$ \\
\hline 110 & 360,9 & 9 & 2 & 26 & 169,1 & 126,9 & $21.455,2$ & 4,3 & $85 \%$ & $86 \%$ \\
\hline 120 & 393,7 & 10 & 2 & 28 & 184,5 & 138,4 & $25.533,5$ & 4,7 & $85 \%$ & $86 \%$ \\
\hline
\end{tabular}

\section{Levantamento de campo}

O levantamento de campo foi realizado na ocasião dos exames, seguindo a metodologia utilizada e proposta por Medeiros, Patriota e Torres ${ }^{10}$. Contudo, o planejamento da perícia ensejou o levantamento prévio de informações atualizadas sobre o local, as quais incluíram: pesquisa de imagens de satélite, da área aproximada do terreno, da altura estimada da vegetação, das condições de risco, climáticas, geográficas e de vizinhança.

Foram realizados três voos manuais sob rotas programadas com base em imagens de satélite, sendo uma com visada ortogonal ao solo (visada "nadir"), a uma altura de aproximadamente 70 metros; e dois voos com visada oblíqua, a uma altura aproximada de 60 metros, a fim de mapear a área onde teria ocorrido 0 parcelamento irregular do solo e os danos ambientais decorrentes. Durante o voo, o equipamento foi programado para obtenção automática de imagens com intervalo de 2 segundos, tendo registrado um total de 240 imagens.

O tempo total despendido foi de cerca de 1 hora, compreendendo o tempo de preparação, sobrevoo e guarda do equipamento. Para cada voo foram gastos aproximadamente 12 minutos, totalizando cerca de 36 minutos de tempo líquido acumulado. 


\section{Processamento}

As imagens capturadas foram separadas e analisadas com o intuito de verificar o atendimento aos requisitos técnicos previamente estabelecidos para 0 processamento digital fotogramétrico, e para tal recorreu-se a um software tipicamente utilizado para este fim. O processamento de imagens durou aproximadamente oito horas, ou seja, o equivalente a duração de um dia útil de serviço, em dedicação exclusiva.

Na primeira fase do processamento, o software realizou a sobreposição das imagens, objetivando o estabelecimento de pontos correspondentes, que permitiram estimar o posicionamento da câmera em cada uma das fotografias, possibilitando assim a criação de um modelo de nuvem de pontos esparsos, fundamental para a construção do modelo 3D. Para tal o sistema utilizou as informações presentes nos metadados de cada imagem, incluindo dimensão em pixel, distância focal, altitude e coordenadas geográficas (latitude e longitude).

A seguir, com base nas posições estimadas da câmera, o programa calculou e combinou as informações de cada fotografia, o que possibilitou a montagem de nova nuvem de pontos densos, a partir da qual é possível o desenvolvimento de um Modelo de Malha Poligonal (polygonal mesh model), modelo digital de superfície (MDS), um Ortomosaico ou um Modelo Digital de Elevação (DEM - Digital Elevation Model). Evidentemente, a opções aqui descritas estavam presentes no software por nós utilizado, sendo possível que existam variações.

Ortomosaicos são mosaicos construídos digitalmente, através de softwares que unem ortofotos a partir de pontos homólogos identificados em duas ou mais imagens, mantendo os objetos em suas posições ortográficas verdadeiras ${ }^{10}$. Como possuem escala constante, o ortomosaico possibilita a medição direta de distâncias, áreas e ângulos, permitindo a reconstrução de feições planimétricas e, portanto, a elaboração de mapas temáticos ou plantas de situação com precisão, rapidez e a baixo custo ${ }^{10}$.

Em nosso estudo o ortomosaico da área periciada apresentou a resolução espacial de sua distância amostral do solo (ou Ground Sample Distance - GSD) em $2,33 \mathrm{~cm} /$ pixel; isto é, cada pixel da imagem representa $2,33 \mathrm{~cm}$ do terreno. Outrossim, o aerolevantamento possibilitou a geração de uma imagem raster utilizável em sistemas de informações geográficas para geoprocessamento, por meio de exportação em arquivo de extensão ".TIFF" (Figura 1). 


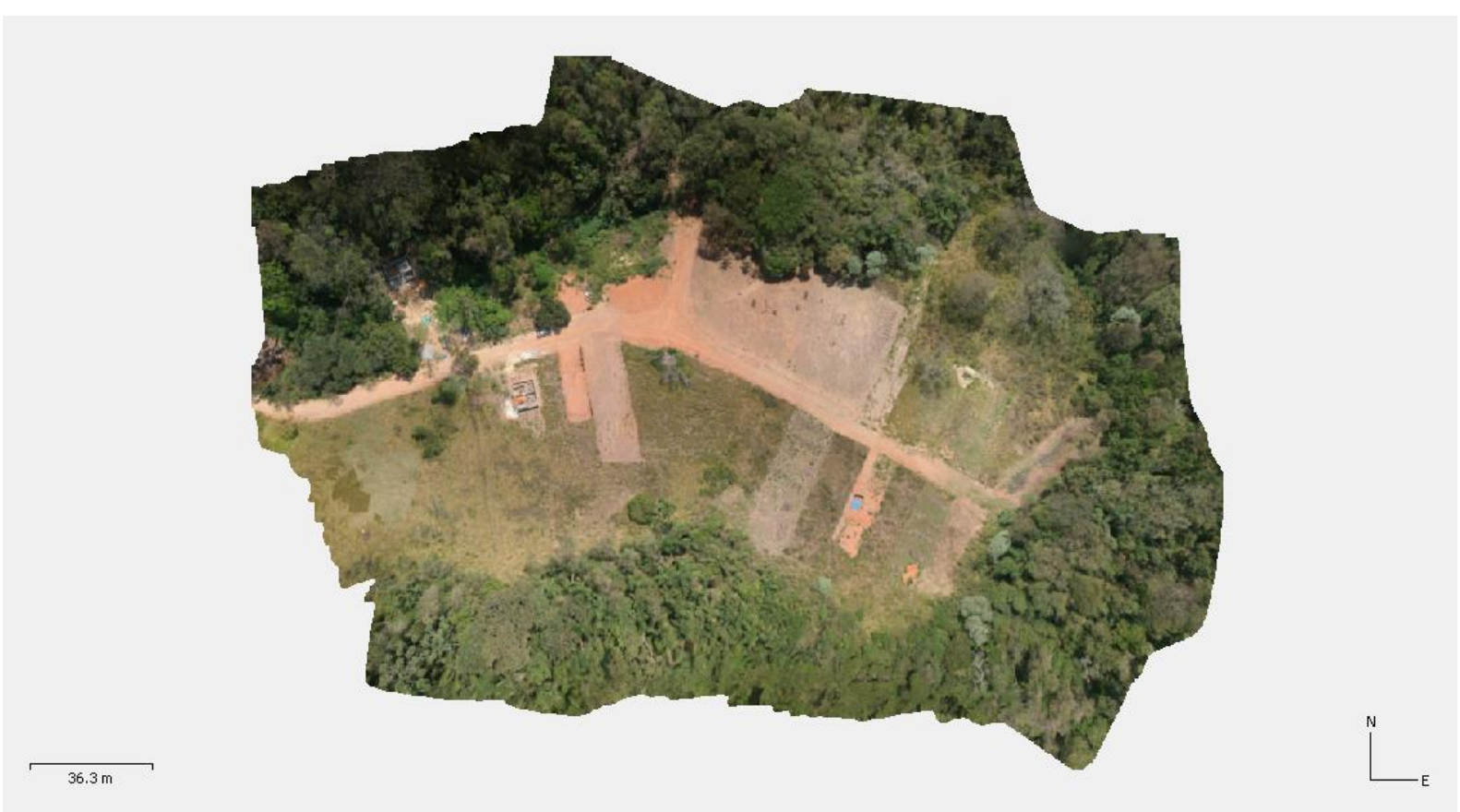

Figura 1. Ortomosaico convencional.

\section{Pós-processamento: a análise do impacto ambiental}

Conforme o disposto no Artigo $1^{\circ}$ da Resolução n.ำ 001/86 do Conselho Nacional do Meio Ambiente (CONAMA ${ }^{17}$, considera-se impacto ambiental qualquer alteração das propriedades físicas, químicas e biológicas do meio ambiente, causada por qualquer forma de matéria ou energia resultante das atividades humanas que, direta ou indiretamente, afetam: I - a saúde, a segurança e o bem-estar da população; II as atividades sociais e econômicas; III - a biota; IV - as condições estéticas e sanitárias do meio ambiente; $\mathrm{V}$ - a qualidade dos recursos ambientais.

Nesse sentido, faz-se oportuno trazer à baila o conceito de meio ambiente, de origem legal, como sendo "o conjunto de condições, leis, influências e interações de ordem física, química e biológica, que permite, abriga e rege a vida em todas as suas formas"18.

No arco dessas afirmações e, considerando que "o dano ao meio ambiente ocorre quando ocorre alteração adversa do meio ambiente" (Almeida, 2014, p.287) ${ }^{19}$, é possível deduzir que houve impacto ambiental negativo e dano ao meio ambiente, caracterizado pela supressão da vegetação outrora existente no local, observada por meio de fotografia de satélite retirada do Google, em data anterior a do exame (vide Figura 2). 


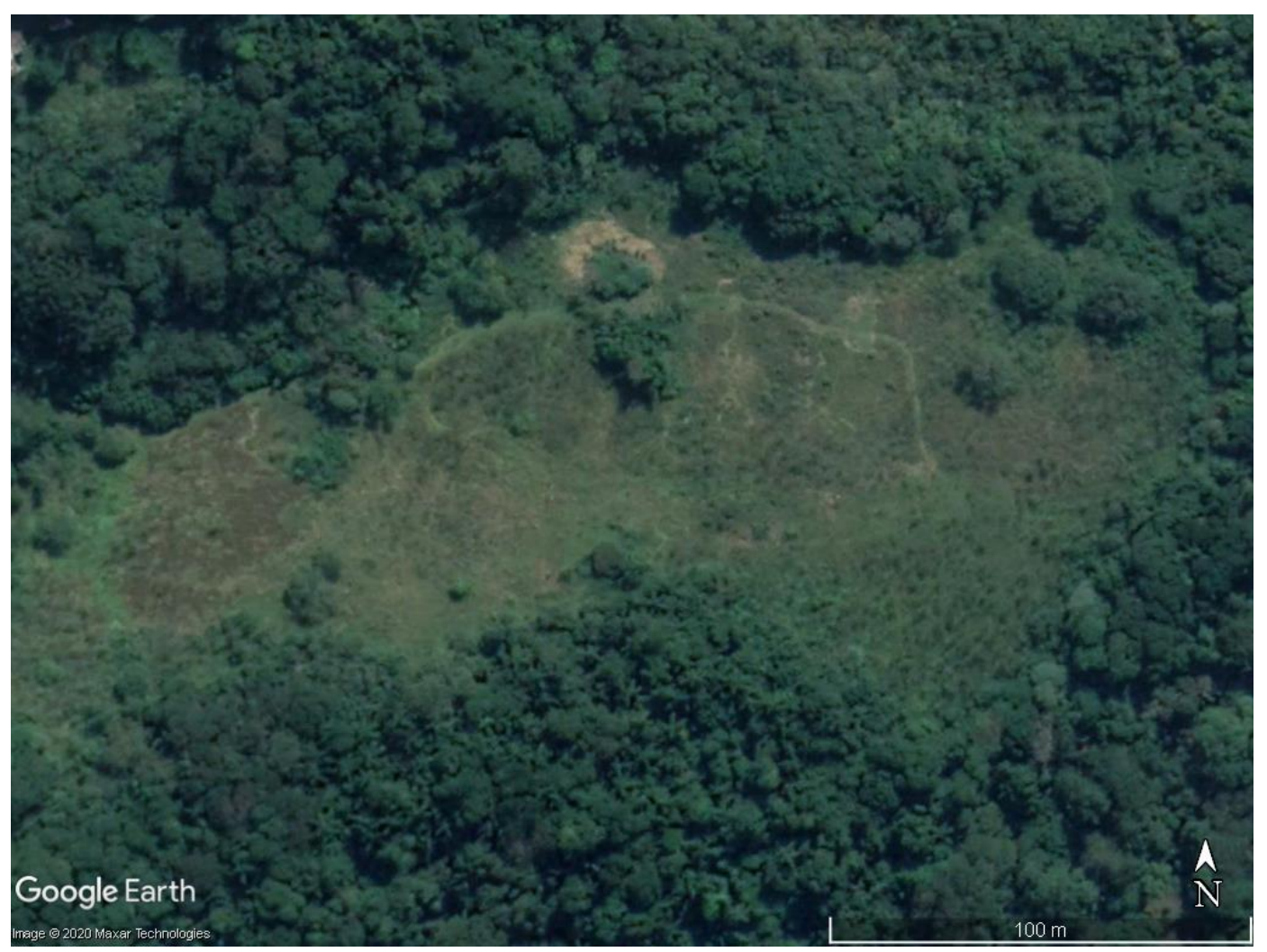

Figura 2. Imagem de satélite do local, extraída do aplicativo Google Earth $\AA$, onde se observa a vegetação em 2018.

Apesar de não ser possível determinar a data em que a supressão de vegetação ocorreu, sobretudo devido à ausência de elementos materiais que permitissem precisar o momento do fato, pode-se oferecer à autoridade requisitante uma estimativa de que tenha se iniciado entre os meses de abril de 2018 (data da imagem de satélite) e setembro de 2019 (data do exame pericial).

Ademais, corroborando o que ficou evidenciado pelo ortomosaico do sítio dos fatos, o exame in loco permitiu a constatação de elementos que denotavam a existência de parcelamento do solo, caracterizados por estacas de madeiras encravadas na terra, as quais poderiam indicar demarcações no terreno para este fim, conforme mostrado pela Figura 3.

Conforme Alvarenga $(2008)^{20}$, o parcelamento do solo urbano trata da divisão do solo, podendo ocorrer na forma de loteamentos ou desmembramentos. Neste sentido, considerando-se que o lote é o produto do parcelamento, é possível inferir que houve o parcelamento do solo na área de circunscrição dos fatos. 


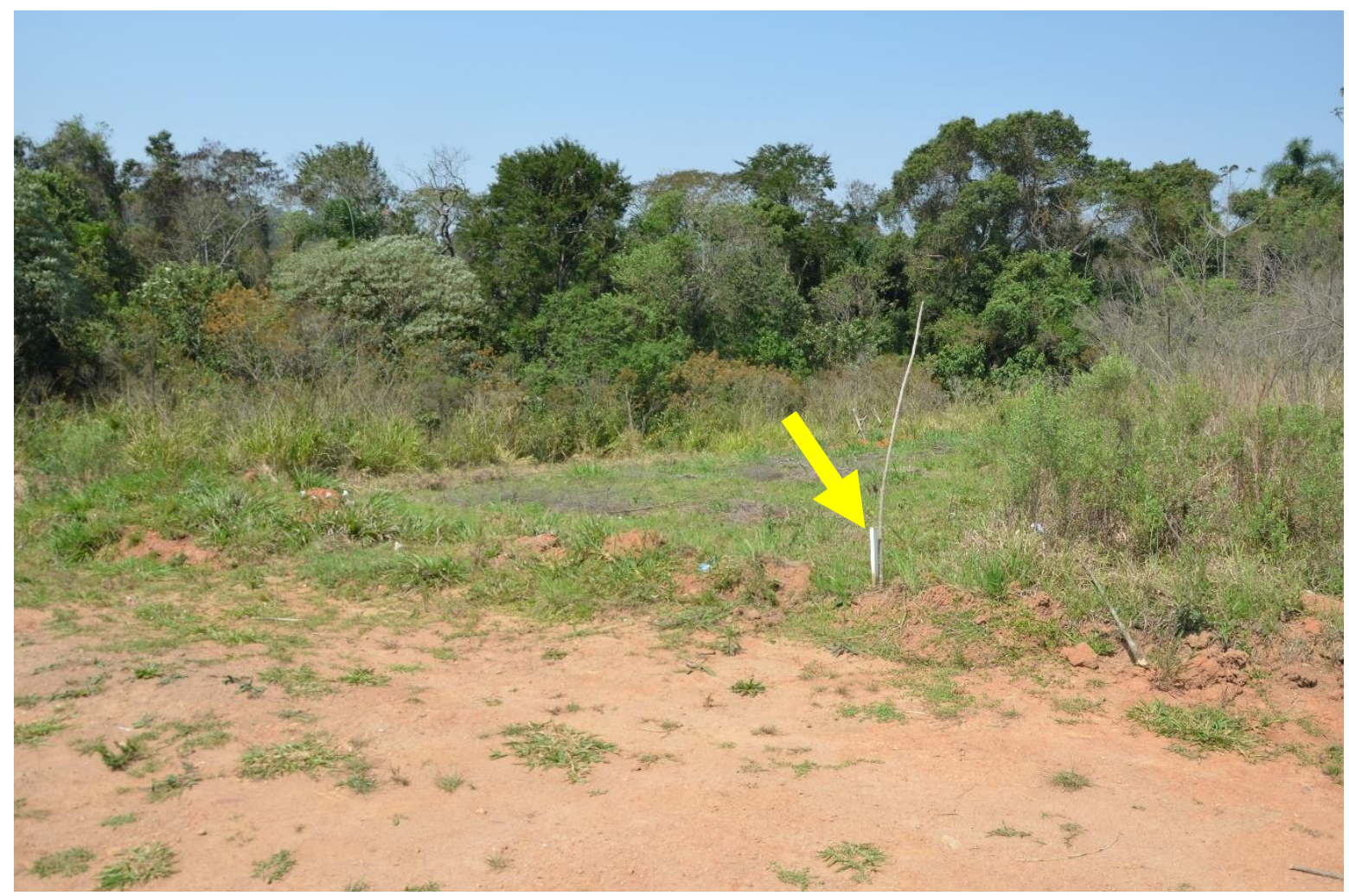

(a)

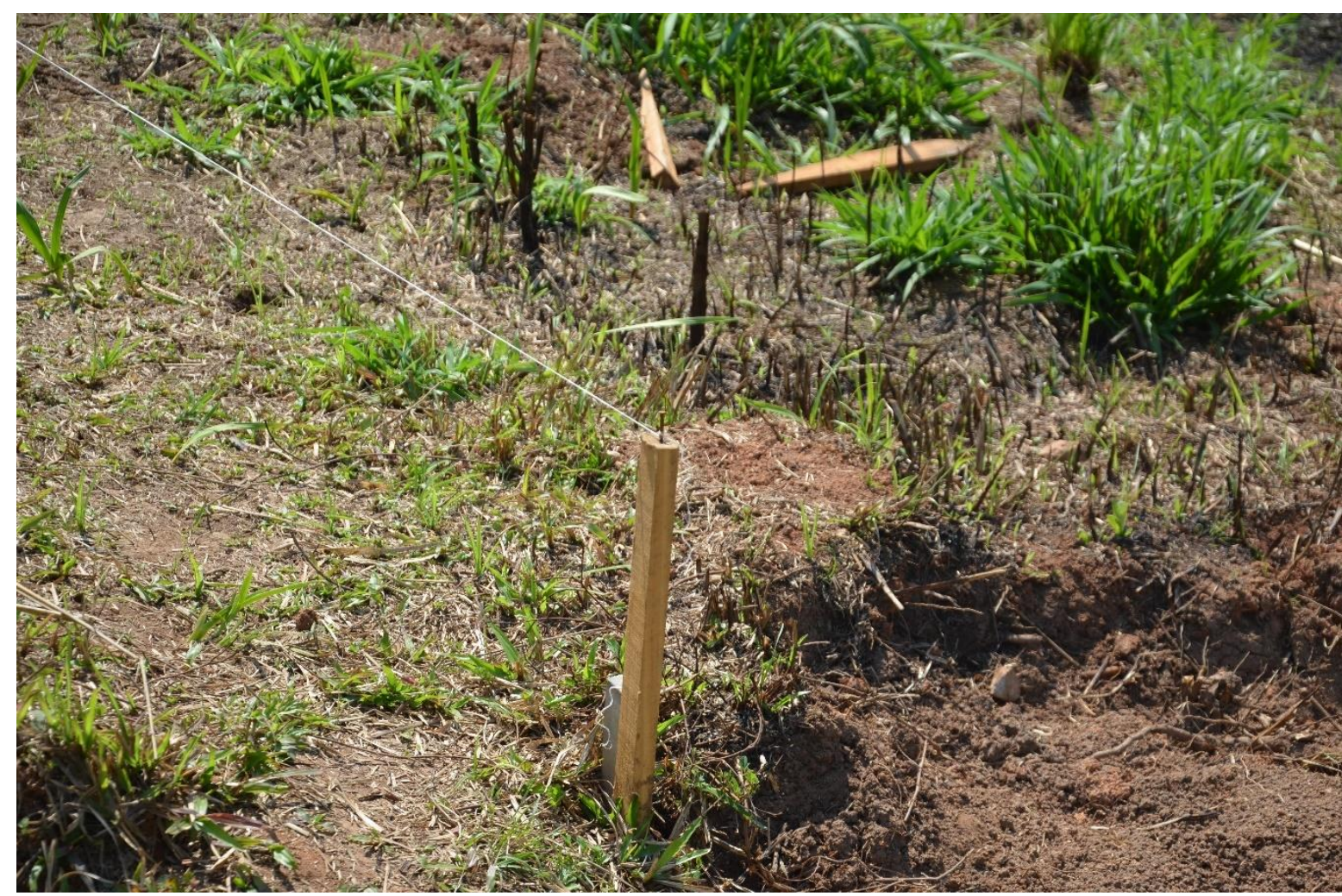

(b)

Figura 3. (a) Demarcação de lotes no local. Note a existência de estaca encravada na terra para este fim; (b) outro exemplo de demarcação de lotes constatado no local, caracterizado pela presença de estacas de madeira na terra. 
Contudo, o autor salienta que todo loteamento deve ser aprovado pela prefeitura e submetido a registro no Cartório de Registro de Imóveis e que, principalmente devido à omissão dos poderes competentes no sentido de velarem pela aplicação da lei, muitos loteamentos têm ocorrido de forma irregular (embora aprovado o projeto, o loteamento não é inscrito no Registro de Imóveis ou tem sua execução em desconformidade com as plantas aprovadas) ${ }^{20}$.

\section{Considerações finais}

A perícia ambiental é recente no país, sendo importante o desenvolvimento e a divulgação de pesquisas científicas na área para a aplicação em exames de casos concretos $^{21}$. Essa modalidade forense é multidisciplinar, complexa e exige que os profissionais sejam capazes de interpretar dados a partir da aplicação das ferramentas tecnológicas disponíveis. Neste sentido, reforçam-se os achados para que os órgãos periciais possibilitem a aplicação de novas tecnologias na coleta de dados dos levantamentos de locais, fornecendo informações técnicas de caráter definitivo com métricas bem definidas.

Está cada vez mais acessível ao perito criminal a construção de sua própria base de dados geográficos com imagens de alta resolução, obtidas pela fotogrametria digital a partir de aeronaves remotamente pilotadas ${ }^{16}$. $O$ presente relato de caso corroborou os achados de Jerry Davis ${ }^{16}$, do Departamento de Geografia e Meio Ambiente da Universidade de São Francisco (EUA), confirmando que a aeronave do tipo multirrotor, da marca DJI, modelo SPARK, pode ser empregada em trabalhos em pequenas áreas, apesar de ser um modelo pouco robusto. Contudo, mediante os devidos cuidados com o planejamento de voo e a consciência de suas limitações, mostrou-se como uma alternativa versátil para a aplicação mais simples em fotogrametria. Tal conclusão pode ser estendida a demais modelos baratos de aeronave, desde que possuam também um GPS embarcado.

Contudo, considerando o caso em questão, é necessário garantir a compatibilidade entre o nível de análises e as conclusões sobre a intervenção antrópica (supressão de vegetação e parcelamento do solo); bem como dos elementos naturais previamente existentes antes do dano (vegetação outrora existente). Assim, a utilização do ortomosaico obtido, bem como das imagens de satélite do Google, possuem ressalvas que devem ser observadas em todas as 
perícias: utilização apenas como referências de localização, estudo prévio da perícia e análises temporais simplificadas ${ }^{22}$.

Há um conceito difundido de que a prova pericial deva ser conclusiva e inconteste, não podendo ser revertida ou contra argumentada ao ser apresentada em juízo. Sob esse prisma, os dados, as ferramentas e a metodologia empregada, em tese, deveriam necessariamente conter caráter conclusivo e inconteste o que, considerando o caso em tela, poderia gerar questionamentos a respeito da ausência de critérios de precisão posicional e de eventuais erros geométricos ou distorções passíveis de ocorrerem com o uso de fotogrametria, principalmente em se tratando do uso de um equipamento de baixo custo, o que implica em uma baixa robustez, câmera de baixa resolução e com possíveis distorções radiais.

Lado outro, os eminentes peritos criminais Jesus Antonio Velho, Gustavo Caminoto Geiser e Albieri Espindula ${ }^{23}$ defendem que, ainda que o método de análise não permita que se chegue a uma resposta categórica sobre determinado assunto, se tal imprecisão for conhecida e os limites dessa análise encontrarem-se consignados no laudo, o resultado pode ainda servir aos interesses da criminalística, uma vez que instrui o processo, ainda que parcialmente, quanto às características do objeto de perícia e às limitações para se obterem maiores informações.

Por mais que essa consideração possa soar inadequada às autoridades requisitantes, que esperam uma resposta sólida aos seus quesitos, cabe ao perito criminal deixar clara no laudo a sua opção por uma determinada metodologia em detrimento de outra, frente às suas dificuldades e restrições; e, aos operadores do Direito, o debate acerca daquela que seria a mais adequada para o caso em tela ${ }^{23}$.

Nesse sentido, é importante trazer à baila a seguinte reflexão por parte dos autores: "até que ponto podem as ciências forenses valerem-se de métodos ainda em fase de testes e desenvolvimento? Não é o laudo pericial apenas a afirmação indubitável de algo concluído com base em exames sólidos sobre vestígios do crime? A resposta é não" (Velho, Geiser, Espindula, 2017, p.7) ${ }^{23}$. Isso porque, no sistema judiciário brasileiro, o magistrado conclui pela livre apreciação da prova, podendo o perito se valer da metodologia possível de ser aplicada frente aos recursos que possui, deixando explícitas suas limitações no corpo do laudo.

Por conseguinte, as técnicas utilizadas na criminalística, como quaisquer outras técnicas científicas, devem ser colocadas à prova constantemente seguindose o mesmo rigor científico em sua contestação. Considerando a rápida evolução 
das tecnologias e das ciências forenses, uma revisão pode vir a ser ainda mais comum, sendo a perícia novamente realizada, à luz de novas técnicas, possibilitando novas respostas ${ }^{23}$.

No arco dessas afirmações e com ciência das suas limitações, o presente relato de caso apresentou uma possibilidade quanto à obtenção de elementos técnicos de aplicação pericial com o uso da tecnologia de aquisição de imagens por meio de veículos aéreos não tripulados de pequeno porte, mais acessíveis ao perito criminal que não dispõe de equipamentos mais robustos em seus institutos de criminalística. Por este motivo, os profissionais muitas vezes utilizam aeronaves particulares com o único intuito de produzir um laudo pericial de melhor qualidade.

É de conhecimento que a principal expectativa em torno de levantamentos com o uso de drones está relacionada com a possibilidade de se obterem medições planialtimétricas que possibilitem um levantamento topográfico e o cálculo de distâncias, áreas e volumes. Porém, não se pode ignorar sua funcionalidade quanto à realização de fotografias e ortomosaicos, possibilitada pela rapidez e facilidade no uso de uma aeronave de baixo custo, permitindo a frequência de levantamentos e a obtenção de fotografias em regiões de difícil acesso ${ }^{12}$.

Mesmo para uma finalidade um pouco mais simples, é necessário que o perito criminal se atente ao fato de que o laudo pericial deve relatar em detalhes suficientes para que seu método seja reprodutível - esse também um dos princípios da criminalística - por meio da utilização de um planejamento apropriado para o aerolevantamento $^{27}$, como o exposto no presente estudo aplicado a um drone de baixo custo.

Os mapas apresentados no presente relato permitem fornecer aos destinatários do laudo pericial elementos que caracterizam o dano e o impacto ambiental negativo. Considerando que no local dos fatos havia região vegetada, conforme mostrado nas figuras no bojo do presente trabalho, resta evidente que a sua supressão decorrente do parcelamento do solo afetou a qualidade dos recursos ambientais. Nesse sentido, os resultados confirmam os achados de Trauczynski e Fantini $^{24}$, uma vez que os danos ambientais no referido estudo também estiveram relacionados à pressão imobiliária e à construção civil.

Contudo, cabe novamente salientar que a metodologia desenvolvida e aplicada ao exame pericial objeto deste trabalho tem por objetivo tornar possível a obtenção de dados que sejam utilizados para referência de localização, estudo e 
análises temporais simplificadas, levando-se em conta as limitações inerentes à aeronave utilizada.

Destarte, deve-se considerar os dados agregados à presente perícia utilizando-se o drone de baixo custo, ainda que com suas limitações; frente ao exame deste mesmo local sem esse recurso, contando apenas com a câmera fotográfica in loco. Em um primeiro momento, não se deve pensar nesse método comparando-se com o que seria ideal; mas sim considerando as dificuldades enfrentadas pela maioria dos institutos de criminalística do país, que sequer possuem aeronaves remotamente pilotadas, o que poderia ser considerado como um avanço tecnológico quando empregado de forma voluntária pelo perito; além de evidenciar a necessidade de as instituições investirem na aquisição de drones robustos, os quais poderiam, de forma prática, melhorar e facilitar ainda mais o trabalho pericial.

Para trabalhos mais complexos, há a necessidade de efetuarem-se as verificações estatísticas de qualidade (através de Padrões de Exatidão Cartográfica) para obtenção de produtos fotogramétricos (além das ortofotos), por meio da utilização de pontos de checagem, locados e georreferenciados em campo, juntamente com pontos de apoio, estes, utilizados como condição de contorno para o processamento dos dados 5 . O georreferenciamento destes pontos deve ocorrer com a utilização de equipamento de posicionamento geodésico RTK (Real Time Kinectic), devendo ser agregados ao processamento conforme a necessidade da perícia e da geração dos produtos da fotogrametria.

Essa limitação poderia ser contornada por meio do empréstimo de equipamentos GNSS, junto a universidades (aproximando a perícia da Academia), enquanto não ocorre a sua aquisição por parte das instituições periciais. Essa opção pode ser questionável pois deixaria o perito à mercê da boa vontade ou da disponibilidade do equipamento, o qual poderia ser locado por temporada de serviço $^{16}$. Porém, deve-se levar em conta que os ritos de contratação no poder público seguem regras específicas segundo a lei de licitações, o que poderia dificultar e atrasar a realização do exame pericial.

Uma outra limitação, além da necessidade de um GNSS (Global Navigation Satellite System), se dá quanto à necessidade do uso de um computador robusto, além da aquisição da licença do software específico de fotogrametria. Uma alternativa também apresentada pela literatura ${ }^{16}$ seria o processamento dos dados 
por meio do envio das fotos a sites especializados no processamento das imagens (via nuvem de pontos) para obtenção de modelos digitais de superfície (MDS), modelos digitais do terreno (MDT), curvas de nível, ortofotos de índice de vegetação, nuvem de pontos, dentre outros produtos mais robustos.

Finalmente, o emprego dessas ferramentas, aliadas ao uso do drone de baixo custo, poderiam ensejar trabalhos futuros quanto à determinação de altimetria, curvas de nível e declividade; além da construção de modelos avaliação do funcionamento da paisagem, quantidade e qualidade de biomassa disponível, características do terreno e pressão antrópica ${ }^{25}$.

\section{Referências}

1. Brasil. Conselho Nacional do Meio Ambiente (Conama). Resolução $n^{\circ} 237$ de 19 de dezembro de 1997. DOU de 19/12/1997.

2. Almeida JR, Oliveira SG, Panno M. Perícia Ambiental. Rio de Janeiro: Thex, 2003. 205 p.

3. Rambusch F, Bender S. A competência da polícia militar ambiental de Santa Catarina para realizar exame pericial ambiental no processo penal. Revista ordem pública e defesa social. 2011;4(1):55-75.

4. Nicoletti EAM, Ferreira RL. Geotecnologia aplicada à perícia ambiental. Caderno Meio Ambiente e Sustentabilidade. 2015;6(4):37-53.

5. Dalmolin JA. Avaliação do uso da fotogrametria digital em levantamentos topográficos. [Monografia]. Joinville: Centro Tecnológico de Joinville, UFSC; 2018.

6. Cerello RC, Mayrink RR. VANT: a nova arma pericial. Revista Perícia Federal. 2013;XIV(32):8-13.

7. DECEA esclarece normas para voos de drones no Brasil Disponível em: http://www2.fab.mil.br/cenipa/index.php/ultimas-noticias/871-decea-esclarece-normaspara-voos-de-drones-no-brasil Acesso em: 10 fev 2019.

8. García IG. Estudio sobre vehículos aéreos no tripulados y sus aplicaciones. 2017. 196 f. Trabalho de Conclusão de Curso - Escuela de Ingenierias Industriales, Universidad de Valladolid. Disponível em: <http://uvadoc.uva.es/bitstream/10324/23021/1/TFG-P528.pdf>. Acesso em: 18 jan. 2020.

9. Pasqualini A. Drones em perícias de engenharia forense e crimes contra o meio ambiente. Revista A Barriguda. 2016;6:522-537.

10. Medeiros J, Patriota R, Torres S. Proposta de Uso de Drones na Realização de Perícias em Patrimônio Histórico: abordagem experimental nas ruínas da primeira fábrica de 
cimento Portland da América Latina. Revista Brasileira de Ciências Policiais. 2017;8(2):205-221. https://doi.org/10.31412/rbcp.v8i2.503

11. Azambuja JCB. Desenvolvimento de metodologias para engenharia legal e perícia ambiental com aplicações em engenharia de minas e ambiental. In: Salão UFRGS 2016: SIC - XXVIII Salão de Iniciação Científica da UFRGS, Campus do Vale - UFRGS, 2016. Disponível em: <https://lume.ufrgs.br/handle/10183/155068>. Acesso em 09 out 2019.

12. Fonstad MA, Dietrich JT, Courville BC, Jensen JL, Carbonneau PE. Topographic structure from motion: a new development in photogrammetric measurement. Earth Surface Processes and Land-forms. 2013;38(4):421-430. https://doi.org/10.1002/esp.3366

13. Silva Neto M. A semana de mapeamento aéreo urbano Droneng começou. Disponível em: $\quad<$ http://blog.droneng.com.br/semana-de-mapeamento-aereo-urbano-comecou/>. Acesso em:09 out 2019.

14. DJI. Spark. Disponível em: <https://www.dji.com/br/spark>. Acesso em: 11 out 2019.

15. Davis J. Free-Flight Mapping: Pix4Dcapture \& dji Spark. San Francisco State University, Institute for Geographic Information Science. Disponível em: <https://geog.sfsu.edu/sites/default/files/fieldequipment/instructions/SparkMappingGuide _. 0.pdf>. Acesso em 09 out 2019.

16. EMBRAPA. Circular Técnica 75: Planos de Voo Semiautônomos para Fotogrametria com Aeronaves Remotamente Pilotadas de Classe 3. 2018. Disponível em: <https://www.embrapa.br/busca-de-publicacoes/-/publicacao/1100860/planos-de-voosemiautonomos-para-fotogrametria-com-aeronaves-remotamente-pilotadas-de-classe3>. Acesso em 25 set 2019.

17. CONAMA. Resolução oㅡ 001, de 23 de janeiro de 1986. DOU de 17/02/1986. Disponível em: <http://www2.mma.gov.br/port/conama/res/res86/res0186.html>. Acesso em 29 jun 2020.

18. BRASIL. Lei no 6.983, de 31 de agosto de 1981. Dispõe sobre a Política Nacional do Meio Ambiente, seus fins e mecanismos de formulação e aplicação, e dá outras providências. DOU de 02/09/1981.

19. Almeida R. Avaliação de Danos Causados ao Meio Ambiente. In: TOCCHETTO, D. (Org.). Perícia Ambiental Criminal. 3 ed. Campinas: Millennium, 2014. 500 p.

20. Alvarenga LC. O Parcelamento do Solo Urbano. Qualitas Revista Eletrônica. 2007;6(2):1-8.

21. Botteon VW. Aplicabilidade de ferramentas de geotecnologia para estudos e perícias ambientais. Rev. Bras. Crimin. 2016;5(1):7-13. https://doi.org/10.15260/rbc.v5i1.110 
22. Alves RAL, Russo D, Magliano MM, Blum MLB. Fundamentos de Geoprocessamento Aplicado à Perícia. In: Tocchetto D. (Org.). Perícia Ambiental Criminal. 3 ed. Campinas: Millennium, 2014. $500 \mathrm{p}$.

23. Velho JA, Geiser GC, Espindula A. Ciências forenses: uma introdução às principais áreas da criminalística moderna. Campinas: Millennium Editora; 2017. 505 p.

24. Trauczynski RA, Fantini AC. Casuística de perícias criminais em delitos contra a flora em Santa Catarina: áreas de preservação permanente impactadas. Rev. Bras. Crimin. 2014;3(2):7-10. https://doi.org/10.15260/rbc.v3i2.53

25. Tancredi NSH et al. Uso de geotecnologias em laudos periciais ambientais: estudo de caso no município de jacundá. Pará. Revista Geografar. 2012;7(1):1-19. https://doi.org/10.5380/geografar.v7i1.21252 